\title{
The cost of fall-related injuries among older people in NSW, 2006-07
}

\author{
Wendy L. Watson ${ }^{\mathrm{A}, \mathrm{D}}$, Angela J. Clapperton ${ }^{\mathrm{B}}$ \\ and Rebecca J. Mitchell ${ }^{\mathrm{A}, \mathrm{C}}$ \\ ${ }^{\mathrm{A}}$ NSW Injury Risk Management Research Centre, \\ The University of New South Wales \\ ${ }^{\mathrm{B}}$ Monash University Accident Research Centre (formerly ${ }^{\mathrm{A}}$ ) \\ ${ }^{\mathrm{C}}$ Department of Aviation, The University of New South Wales \\ ${ }^{\mathrm{D}}$ Corresponding author.Email:w.watson@unsw.edu.au
}

\begin{abstract}
This study aimed to establish comprehensive estimates of the cost of fall-related injury among older people in NSW. A health service utilisation approach was used to estimate the cost of hospital treatment, residential care and ambulance transport. Other costs were estimated by deriving ratios of inpatient costs to other services from the literature. In the 2006-07 financial year, $251000(27 \%)$ of older people fell at least once and suffered, in total, an estimated 507000 falls. An estimated 143000 medically treated fallrelated injuries among older people resulted in lifetime treatment costs of \$558.5 million. Although only $18 \%$ of these injuries resulted in hospital admission, the cost of care associated with these cases accounted for $84.5 \%$ of the total cost. The cost of fall-related injury among older people in NSW in 2006-07 is a significant increase over earlier estimates and underscores the urgent need for effective preventive efforts across the state.
\end{abstract}

As the New South Wales (NSW) population ages, fallrelated injuries among older adults (aged 65 years and over) will place increased demand on the health system. ${ }^{11-13}$ Fall-related injuries among older people - mainly hip and other fractures - consume a disproportionate share of hospital resources; no other injury cause, including road trauma, costs the NSW health system more. ${ }^{14}$

In recent years there have been a number of international studies that have developed comprehensive estimates of the cost of fall injuries. ${ }^{15-17}$ Estimates of the cost of injuries are necessary to guide decision makers in determining funding priorities and to support cost-effectiveness and cost-benefit analyses of the most effective means of preventing injury.

To date, there has been only one population-level study conducted in NSW which estimated the cost of fall-related injuries. ${ }^{14}$ However, these costs were established in the context of a broader all-age, all-injury study which included limited cost components and is now quite dated. Consequently, a study was commissioned by NSW Health to provide comprehensive, up-to-date estimates of the costs associated with fall-related injuries to underpin the next iteration of the state falls prevention plan and to provide input for cost-benefit analyses of falls prevention programs.

The aim of this study was to quantify the economic burden of injuries associated with falls in people aged 65 years and over in NSW during the 2006-07 financial year. This paper summarises the findings from the study report. ${ }^{18}$

\section{Methods}

The methods are outlined briefly here. A detailed description of the methods can be found in the study report. ${ }^{18}$

\section{Incidence estimation}

In order to develop cost estimates it was necessary to establish the incidence of fall-related injuries for which treatment was sought. Estimates of the incidence of medically treated fall-related injuries were developed using data from several sources. These included the:

- NSW Admitted Patients Dataset to estimate the total number of incident hospital admissions due to falls in older people.

- Victorian Admitted Episodes Dataset and Victorian Emergency Minimum Dataset to establish the ratios of 
admitted to non-admitted emergency department presentations for each gender and 5-year age-group. These ratios were then applied to the estimated number of fallrelated incident hospital admissions to derive an estimate of emergency department attendances for NSW.

- 2009 NSW Falls Prevention Survey, in combination with the NSW estimated resident population, at 31 December 2006, by gender and 5-year age group, derived from Australian Bureau of Statistics online population data ${ }^{19}$ to estimate the number of people who fell, the number of falls experienced and the number of fall-related injuries that were treated in a non-hospital setting.

The selection of the cases from these datasets was confined to persons aged 65 years and over and the following three mutually exclusive categories of care were identified for the purpose of this study: hospital admissions; emergency department presentations (not admitted); and non-hospital treatment (including general practitioners and allied health professionals).

Estimates of the number of emergency and non-emergency ambulance trips and the number of older people living in the community who were transferred to residential aged care following a fall-related hospital admission were also developed to facilitate cost estimation.

\section{Cost estimation}

Costs were estimated separately for each category of care defined in the previous section. Estimated costs included all relevant treatment and care services such as inpatient care (admitted cases only), ambulance, emergency department treatment, outpatient treatment, pharmaceuticals, medical and other health service provision, and residential aged care or home nursing, domestic services and home modifications.

For cost components where there were reasonably solid health service utilisation data available, such as for hospital inpatient care, emergency department treatment, ambulance transport and residential aged care, a 'bottom-up' health service utilisation approach was used.
Inpatient hospital costs were calculated using the Australian-Refined-Diagnosis-Related Group (AR-DRG) codes. Average AR-DRG Version 5.0 costs were applied to each episode of care using data from the NSW Cost of Care Standards 2006/07. ${ }^{20}$ Individuals who attended the emergency department but were not admitted were assigned an average cost and the average cost of emergency and non-emergency ambulance transport was assigned to the estimated number of trips in each category. The cost of respite and permanent residential aged care was calculated using estimates of the number of community-dwelling older people discharged to aged-care facilities following a fall injury and applying average lengths of stay and average cost per place-day. ${ }^{21}$ Costs beyond 1 year were discounted at $5 \%$ per annum in line with current Australian practice. The cost of residential aged care was not included for those already residing in an aged-care facility when they fell.

The cost of other health care services were estimated using ratios developed from the literature of the cost of each service relative to the cost of inpatient care. The ratios for hospital outpatient services, pharmaceuticals, general practitioner, specialist and allied health consultations were derived from falls-specific costs using Australian health expenditures for 1993-94. ${ }^{22}$ The ratios for community nursing and domiciliary services were calculated from Hall and Hendrie. ${ }^{23}$

\section{Results \\ Incidence}

In 2006-07, the NSW population aged 65 years and over was estimated to be just over 931000 people. It was estimated that around 251000 (27\%) older people fell at least once and suffered, in total, an estimated 507000 falls. Almost 28\% (143000) of these falls resulted in an injury requiring some form of medical treatment and, of these, $18 \%$ were serious enough to warrant admission to hospital (Table 1).

While women accounted for $55 \%$ of the population, they accounted for $58 \%$ of all falls. Overall, women were

Table 1. Estimated resident population, number of people who fell and number of medically treated fall injuries by gender, persons aged 65 years and over, NSW, 2006-07

\begin{tabular}{|c|c|c|c|c|c|c|}
\hline & \multicolumn{2}{|c|}{ Men } & \multicolumn{2}{|c|}{ Women } & \multicolumn{2}{|c|}{ Persons } \\
\hline & $n$ & $\%$ & $n$ & $\%$ & $n$ & $\%$ \\
\hline Estimated resident population & 417027 & 44.8 & 514305 & 55.2 & 931332 & 100.0 \\
\hline Number of people who fell & 105088 & 41.8 & 146365 & 58.2 & 251453 & 100.0 \\
\hline Total number of falls & 218156 & 43.0 & 289051 & 57.0 & 507207 & 100.0 \\
\hline All medically treated fall injuries & 51558 & 36.0 & 91415 & 64.0 & 142973 & 100.0 \\
\hline
\end{tabular}


slightly more likely to fall than men $(28.5 \%$ of older women fell compared to $25 \%$ of older men).

Women accounted for $64 \%$ of all medically treated fallrelated injuries (Table 2). They were also more likely than men to suffer an injury requiring medical treatment as a result of a fall (62.5\% of women who fell compared to $49 \%$ of men who fell) and to be hospitalised following a fall ( $12 \%$ of women who fell compared to $7 \%$ of men who fell).

\section{Direct health care costs}

The total direct cost of health care associated with fallrelated injuries in older adults was estimated at $\$ 558.5$ million (Table 3 ). Although only $18 \%$ of medically treated injuries resulted in hospital admission, the cost of care associated with these cases accounted for $84.5 \%$ of the total cost. Treatment costs associated with emergency department presentations accounted for $9 \%$ of the total cost and other non-hospital attendances, which accounted for the $69 \%$ of all medically treated falls, accounted for an estimated $6.5 \%$ of treatment costs.

While women accounted for $64 \%$ of all medically treated fall-related injuries (Table 2), they accounted for $69 \%$ of total treatment costs (Table 3). Total health care costs for women were 2.2 times higher than for men.

Table 4 presents the total treatment and care costs of fall-related injuries among older people in NSW by cost component and level of treatment. The majority of total costs $(57.9 \%)$ were associated with hospital treatment and care (inpatient, emergency department and outpatient) followed by residential aged care $(22.9 \%)$ and non-hospital medical (general practitioner and specialist) treatment $(6.1 \%)$.

The total cost of treatment and care associated with falls among community-dwelling older people in the current study (excluding the cost of any subsequent residential aged care) was compared against that derived by scaling up the costs obtained in a prospective NSW study by Tiedemann et al. ${ }^{24}$ The total estimate derived from this small study was only $5.7 \%$ higher than that of the current study.

\section{Discussion}

This study highlights the significant cost of fall-related injuries among older people in NSW. Although these costs are not all borne by NSW Health, the estimated lifetime cost of treating fall-related injuries among older people in NSW in 2006-07 was equivalent to almost 5\% of the NSW health budget in that year. ${ }^{25}$ In order to reduce the impact on the health system of fall-related injuries among older people, significant resources need to be directed towards the promotion of evidence-based fall-related injury prevention programs at the local level across the state.

At $\$ 558.5$ million, the current estimate of treatment costs for 2006-07 is 2.5 times the previous estimate for 1998-99 of $\$ 224.7$ million. ${ }^{14}$ This is due in part to inflation in health care costs (total health price index) which increased by

Table 2. Estimated number of falls requiring medical treatment by gender and level of treatment, persons aged 65 years and over, NSW, 2006-07

\begin{tabular}{|c|c|c|c|c|c|c|}
\hline \multirow[t]{2}{*}{ Level of treatment } & \multicolumn{2}{|c|}{ Men } & \multicolumn{2}{|c|}{ Women } & \multicolumn{2}{|c|}{ Persons } \\
\hline & $n$ & $\%$ & $n$ & $\%$ & $n$ & $\%$ \\
\hline Hospital admissions & 7798 & 15.1 & 17763 & 19.4 & 25561 & 17.9 \\
\hline Emergency department attendances & 5732 & 11.1 & 12734 & 13.9 & 18466 & 12.9 \\
\hline Non-hospital treatments & 38028 & 73.8 & 60918 & 66.7 & 98946 & 69.2 \\
\hline All medically treated fall injuries & 51558 & 100.0 & 91415 & 100.0 & 142973 & 100.0 \\
\hline
\end{tabular}

Table 3. Estimated health care costs for all medically treated fall-related injuries by gender and level of treatment, persons aged 65 years and over, NSW, 2006-07

\begin{tabular}{|c|c|c|c|c|c|c|}
\hline \multirow[t]{2}{*}{ Level of treatment } & \multicolumn{2}{|c|}{ Men } & \multicolumn{2}{|c|}{ Women } & \multicolumn{2}{|c|}{ Persons } \\
\hline & (\$ millions) & $\%$ of total & (\$ millions) & $\%$ of total & (\$ millions) & $\%$ of total \\
\hline Hospital admissions & 141.17 & 81.4 & 330.43 & 85.8 & 471.60 & 84.4 \\
\hline Emergency department attendances & 21.76 & 12.5 & 28.38 & 7.4 & 50.16 & 9.0 \\
\hline Non-hospital treatments & 10.59 & 6.1 & 26.12 & 6.8 & 36.71 & 6.6 \\
\hline Total NSW & 173.52 & 100.0 & 384.93 & 100.0 & 558.46 & 100.0 \\
\hline Average cost $(\$)$ & 3336 & & 4211 & & 3906 & \\
\hline
\end{tabular}


Table 4. Estimated health care costs for all medically treated fall-related injuries by level of treatment and cost component, persons aged 65 years and over, NSW, 2006-07

\begin{tabular}{|c|c|c|c|c|}
\hline \multirow{2}{*}{ Cost component } & \multicolumn{4}{|c|}{ Total cost } \\
\hline & $\begin{array}{l}\text { Admissions } \\
\text { (\$ millions) }\end{array}$ & $\begin{array}{l}\text { Emergency department } \\
\text { attendances } \\
\text { (\$ millions) }\end{array}$ & $\begin{array}{l}\text { Non-hospital } \\
\text { treatments } \\
\text { (\$ millions) }\end{array}$ & Total \\
\hline Hospital inpatient ${ }^{a}$ & 262.68 & - & - & 262.68 \\
\hline Emergency department and outpatient ${ }^{\mathrm{b}}$ & 35.16 & 25.73 & - & 60.89 \\
\hline Total hospital sector & 297.84 & 25.73 & - & 323.57 \\
\hline Residential aged care & 127.90 & - & - & 127.90 \\
\hline Medical treatments & 10.96 & 7.14 & 16.06 & 34.16 \\
\hline Pharmaceuticals & 2.92 & 2.01 & 4.26 & 9.19 \\
\hline Allied health & 6.16 & 4.04 & 8.86 & 19.06 \\
\hline Ambulance & 14.56 & 7.50 & - & 22.04 \\
\hline Community nursing & 4.56 & 1.51 & 3.05 & 9.12 \\
\hline Domiciliary services & 6.71 & 2.23 & 4.49 & 13.42 \\
\hline Total & 471.60 & 50.16 & 36.71 & 558.46 \\
\hline
\end{tabular}

$28 \%$ over that period ${ }^{26}$ the impact of the ageing population (the number of people aged 65 years and over in NSW increased by $14.5 \%{ }^{19}$ ) and an increase in the agestandardised rate of falls hospitalisations by a similar magnitude over the same period. ${ }^{27}$ The earlier study also did not include all episodes of hospital care (only the index admission), the cost of residential aged care, outpatient costs, community nursing, domiciliary services or the costs associated with people who did not attend the hospital system for treatment.

The main limitation of this study lies in the lack of health service utilisation data in which falls and other conditions can be comprehensively identified. Where data was unavailable, particularly for more minor injuries, researchers had to rely on data from various sources or the literature, some of which is quite dated. Where there were inadequacies in existing data, assumptions had to be made.

The limitations of this study highlight the inadequacies in current NSW population health data and several recommendations are made to address these shortcomings. These include: the introduction of a unique patient identifier and the date of injury in the hospital discharge dataset to facilitate the identification of incident cases of fall-related hospitalisations in the NSW Admitted Patients Dataset; and the standardisation of the NSW emergency department data collections across all hospitals in terms of the coding of injury causes and diagnoses to facilitate the quantification of the number of falls resulting in emergency department attendance and their associated costs.

The study also highlighted the limitations in our understanding of the patient journey, beyond the hospital, following a fall. While there has been some research into the costs associated with falls in small samples of the population, ${ }^{23,24}$ there is an urgent need for research at the population level to establish the utilisation of services beyond the hospital door.

Despite these limitations, the study represents the most comprehensive estimate of the cost of falls in NSW to date as it includes the majority of cost components associated with medical treatment and care following a fall-related injury. The estimates derived in this study were also validated against those derived by scaling up from a small, community-based study.

\section{Conclusion}

This study demonstrates the high economic cost of falls in older people and underscores the need for a strategically focused falls prevention strategy for NSW and for the support of cost-effective falls prevention in this population. It also highlights the need for improvements in population health data in NSW to facilitate the estimation of incidence and costs for the different levels of care provided.

The full report, The Incidence and Cost of Falls Injury Among Older People in New South Wales 2006/07, is available at: http://www.health.nsw.gov.au/pubs/2010/ costoffall.html

\section{Acknowledgments}

W Watson and A Clapperton were supported by the NSW Department of Health. R Mitchell was partially supported by the NSW 
Department of Health and by an Australian Research Councillinkage post-doctoral fellowship (LP0990057).

The authors wish to thank the Centre for Epidemiology and Research at the NSW Department of Health for providing access to the Health Outcomes and Information Statistical Toolkit (HOIST) to obtain the hospital data analysed in this study. The HOIST system refers to a data access, analysis and reporting facility established and operated by the Centre for Epidemiology and Research, NSW Department of Health.

The authors would also like to acknowledge the contribution of: the Monash University Accident Research Centre for providing aggregated hospital and Emergency Department data; the NSW Population Health Survey team for the provision of preliminary data from the 2009 Falls Prevention Survey; and the Ambulance Service of NSW for the provision of average unit cost data.

\section{References}

1. Campbell AJ, Borrie MJ, Spears GF. Risk factors for falls in a community-based prospective study of people 70 years and older. J Gerontol 1989; 44(4): M112-7.

2. Morris M, Osborne D, Hill K, Kendig H, Lundgren-Linquist B, Browning C. Predisposing factors for occasional and multiple falls in older Australians who live at home. Aust J Physiother 2004; 50(3): 153-9.

3. Nevitt MC, Cummings SR, Kidd S, Black D. Risk factors for recurent nonsyncopal falls: a prospective study. JAMA 1989; 261(18): 2663-8. doi:10.1001/jama.261.18.2663

4. Tinetti ME, Speechley M, Ginter SF. Risk factors for falls among elderly persons living in the community. N Engl J Med 1988; 319(26): 1701-7. doi:10.1056/NEJM198812293192604

5. Sattin RW. Falls among older persons: a public health perspective. Annu Rev Public Health 1992; 13: 489-508. doi:10.1146/annurev.pu.13.050192.002421

6. Tinetti ME, Powell L. Fear of falling and low self-efficacy: a cause of dependence in elderly persons. J Gerontol 1993; 48(Spec No): $35-8$.

7. King MB, Tinetti ME. Falls in community-dwelling older persons. J Am Geriatr Soc 1995; 43(10): 1146-54.

8. Downton J, Andrews K. Postural disturbance and psychological symptoms amongst elderly people living at home. Int J Geriatr Psychiatry 1990; 5(2): 93-8. doi:10.1002/gps.930050206

9. Chung MC, McKee KJ, Austin C, Barkby H, Brown H, Cash S et al. Posttraumatic stress disorder in older people after a fall. Int J Geriatr Psychiatry 2009; 24(9): 955-64. doi:10.1002/ gps.2201

10. Tinetti ME, Williams C. Falls, injuries due to falls, and the risk of admission to a nursing home. $N$ Engl J Med 1997; 337(18): 1279-84. doi:10.1056/NEJM199710303371806

11. Moller J. Projected costs of fall related injury to older persons due to demographic change in Australia. Canberra: Commonwealth Department of Health and Ageing; 2003.

12. Roudsari BS, Ebel BE, Corso PS, Molinari NA, Koepsell TD. The acute medical care costs of fall-related injuries among the
U.S. older adults. Injury 2005; 36(11): 1316-22. doi:10.1016/ j.injury.2005.05.024

13. Stevens JA, Corso PS, Finkelstein EA, Miller TR. The costs of fatal and non-fatal falls among older adults. Inj Prev 2006; 12(5): 290-5. doi:10.1136/ip.2005.011015

14. Potter-Forbes M, Aisbett C. Injury Costs: A Valuation of the Burden of Injury in New South Wales 1998-1999. Sydney: NSW Injury Risk Management Research Centre; 2003.

15. Carroll NV, Slattum PW, Cox FM. The cost of falls among the community-dwelling elderly. J Manag Care Pharm 2005; 11(4): $307-16$.

16. Scuffham P, Chaplin S, Legood R. Incidence and costs of unintentional falls in older people in the United Kingdom. J Epidemiol Community Health 2003; 57(9): 740-4. doi:10.1136/jech.57.9.740

17. Stevens JA, Corso PS, Finkelstein EA, Miller TR. The costs of fatal and non-fatal falls among older adults. Inj Prev 2006; 12(5): 290-5. doi:10.1136/ip.2005.011015

18. Watson W, Clapperton A, Mitchell R. The Incidence and Cost of Falls Injury Among Older People in New South Wales 2006/07. North Sydney: NSW Department of Health; 2010. Available from: http://www.health.nsw.gov.au/pubs/2010/ costoffall.html

19. Australian Bureau of Statistics. 3201.0 Population by Age and Sex, Australian States and Territories, Jun 2008. Australian Bureau of Statistics; 2008.

20. NSW Department of Health. NSW Costs of Care Standards 2006/07. North Sydney: NSW Department of Health; 2007.

21. Australian Institute of Health and Welfare. Residential aged care in Australia 2006-07: A statistical overview. Aged care statistics series 26. Canberra: AIHW; 2008.

22. Mathers C, Penm R. Health system costs of injury, poisoning and musculoskeletal disorders in Australia, 1993-94. AIHW cat. no. HWE 12. Canberra: Australian Institute of Health and Welfare; 1999.

23. Hall SE, Hendrie DV. A prospective study of the costs of falls in older people living in the community. Aust $N Z \mathrm{~J}$ Public Health 2003; 27(3): 343-51. doi:10.1111/j.1467-842X.2003. tb00405.x

24. Tiedemann AC, Murray SM, Munro B, Lord SR. Hospital and non-hospital costs for fall-related injury in community-dwelling older people. N S W Public Health Bull 2008; 19(9-10): 161-5. doi:10.1071/NB07022

25. NSW Department of Health. Annual Report 2006/07. North Sydney: NSW Department of Health; 2007.

26. Australian Institute of Health and Welfare. Health expenditure Australia 2006-07. Canberra: AIHW; 2008.

27. Population Health Division. The Health of the People of New South Wales - Report of the Chief Health Officer, Data Book Injury \& Poisoning. North Sydney: NSW Department of Health; 2008. 